\title{
The Application of Cytogenetics and Fluorescence In Situ Hybridization to Fine-Needle Aspiration in the Diagnosis and Subclassification of Renal Neoplasms
}

Michael H. Roh, MD, PhD'; Paola Dal Cin, PhD²; Stuart G. Silverman, MD³; and Edmund S. Cibas, MD²

BACKGROUND: Percutaneous fine-needle aspiration (FNA) cytology is an important diagnostic test for the evaluation and management of selected renal masses. Cytogenetic analysis of cytology specimens can serve as an adjunct for precise classification because certain tumors are associated with specific chromosomal aberrations. This study summarizes our experience with the application of conventional cytogenetics and fluorescence in situ hybridization (FISH) to renal FNA specimens. METHODS: All percutaneous renal FNAs performed during 2005 through 2008 were identified from the electronic pathology database. Results of cytogenetic and FISH analyses were correlated with the final diagnoses of the renal FNAs. RESULTS: A total of 303 renal FNAs were performed. During an onsite assessment, a portion of the cytology specimen was allocated for cytogenetic analysis in 74 cases. Karyotypic analysis or FISH was successful in 44 (59\%) of these. Characteristic chromosomal abnormalities were observed in 27 cases. In 17 cases, a karyotype revealed a combination of trisomies/tetrasomies and in another 5 cases, FISH revealed trisomy 7 and 17, both of which are consistent with papillary renal cell carcinoma (RCC). Two cases showed 3p deletions consistent with clear cell RCC. Trisomy 3 was observed in 1 case of clear cell RCC. Monosomy 1 and 17 was observed in a case of papillary RCC comprised oncocytic cells. In 1 case of primary renal synovial sarcoma, FISH revealed a rearrangement at the SYT locus (18q11.2). CONCLUSIONS: Renal FNA specimens are amenable to analysis by cytogenetics and FISH in the diagnosis and subclassification of renal neoplasms. Cancer (Cancer Cytopathol) 2010;118:137-45. (c) 2010 American Cancer Society.

KEYWORDS: kidney, fine-needle aspiration, percutaneous biopsy, cytology, cytogenetics, fluorescence in situ hybridization, renal cell carcinoma.

\footnotetext{
Corresponding author: Michael H. Roh, MD, PhD, Department of Pathology, University of Michigan Medical School, $2 \mathrm{G} 332$ UH, $1500 \mathrm{E}$. Medical Center Drive, Ann Arbor, Ml 48109-5054; Fax: (734) 763-4095; mikro@med.umich.edu

${ }^{1}$ Department of Pathology, University of Michigan Medical School, Ann Arbor, Michigan; ${ }^{2}$ Department of Pathology, Brigham and Women's Hospital and Harvard Medical School, Boston, Massachusetts; ${ }^{3}$ Department of Radiology, Brigham and Women's Hospital and Harvard Medical School, Boston, Massachusetts

The authors thank Catherine Johannessen, Ann Thomas, and Deborah Sandstrom for their excellent technical support.
}

Received: October 27, 2009; Revised: January 13, 2009; Accepted: February 12, 2010

Published online: April 28, 2010 in Wiley InterScience (www.interscience.wiley.com)

DOI: 10.1002/cncy.20077, www.interscience.wiley.com 
Percutaneous biopsy serves as an important diagnostic modality for the evaluation and management of selected renal masses. ${ }^{1,2}$ Many renal mass biopsies are now performed using fine (19 gauge or thinner) needles. ${ }^{2}$ Fine needles are generally considered safer than larger needles and a diagnosis can be made based on cytomorphology, especially in patients who are not candidates for a nephrectomy. In a patient with a renal mass undergoing cryoablation, radiofrequency ablation, or ethanol injection, fine-needle aspiration (FNA) may be the only opportunity to gain diagnostic insight into the nature of the renal mass. ${ }^{3}$ Furthermore, a benign diagnosis (eg, angiomyolipoma) can result in the avoidance of unnecessary surgery. In patients who are poor surgical candidates (eg, those with a solitary kidney, a history of a prior nephrectomy, and a comorbid condition), recognition of a good-prognosis subtype of renal cell carcinoma (RCC; eg, papillary or chromophobe) can help guide conservative therapy such as partial nephrectomy or ablation. Thus, it is important to diagnose renal masses on FNA as accurately as possible.

The accuracy of FNA alone in distinguishing benign from malignant renal masses ranges from $73 \%$ to $94 \%{ }^{4}$ When renal cell carcinoma (RCC) is diagnosed, accurate subclassification is achieved in $74 \%$ of cases. ${ }^{5}$ In some cases, accurate diagnosis and assignment of the RCC subtype can be difficult; thus, adjuncts to routine cytomorphologic evaluation of renal FNA specimens have been a topic of active investigation.

Renal tumors are frequently associated with clonal cytogenetic abnormalities; thus, conventional cytogenetic and FISH analyses could serve a crucial role in the diagnosis and subclassification of renal neoplasms, especially RCC. ${ }^{6}$ Specifically, the clear cell, papillary, and chromophobe variants of RCC are associated with $3 p$ deletions, a combination of trisomies, and a combination of monosomies, respectively. Many studies that have investigated cytogenetic abnormalities in renal tumors evaluated tissue obtained from nephrectomy specimens. In contrast, there are only a limited number of case reports and no series to date in the literature that addresses the application of cytogenetics to renal FNAs. The aim of this report is to summarize our experience in the application of karyotypic and FISH analyses to FNAs of renal masses.

\section{MATERIALS AND METHODS}

After approval by the institutional review board, a search of medical records for all percutaneous renal FNA procedures performed at Brigham and Women's Hospital from 2005 through 2008 was conducted. A total of 303 FNAs were performed during this time period; cytologic specimens were obtained using fine (20-gauge, 23-gauge, and/ or 25 -gauge) needles by a radiologist using imaging guidance. Aspirated material was smeared onto glass slides. Some smears were allowed to air dry and were stained with the Hemacolor stain (Harleco, EM Science, Gibbstown, NJ). The remaining smears were fixed by direct immersion in $95 \%$ ethanol or by spray-fixation with a commercial isopropanol-based solution (Protocol Cytologic Fixative; Fisher Scientific, Kalamazoo, Mich), followed by staining with a modified Papanicolaou staining procedure. The rapid evaluation of adequacy was performed using the Hemacolor-stained smears, and 1 to 2 additional passes dedicated to the needle rinse were recommended when this was judged potentially useful, especially in cases where cytogenetics studies might have added value. The fine needles were rinsed in RPMI media and the needle-rinse specimen was apportioned for cytogenetics and/or preparation of cell blocks. For the latter, the rinse was centrifuged at $1800 \mathrm{rpm}$ for 10 minutes, the pellet congealed with several drops each of plasma and thrombin, and the resulting clot fixed in formalin and embedded in paraffin for sectioning and staining with hematoxylin and eosin.

Cytology results were reported as "nondiagnostic" (ie, insufficient or unsatisfactory for evaluation), "negative for malignancy," "atypical" (suggesting a low probability of malignancy), "suspicious for malignancy" (suggesting a high suspicion of malignancy), "neoplastic cells present," or "positive for malignant cells." These primary diagnostic categories were supplemented by specific diagnoses when possible (eg, angiomyolipoma, oncocytoma, and papillary RCC).

For cases in which a portion of the FNA had been allocated for concurrent cytogenetic analysis during an onsite adequacy assessment, the results of the conventional cytogenetic and/or FISH analysis were correlated with the cytologic interpretations and were not performed in an independent, blinded fashion. Rather, the results of cytogenetic/FISH testing were used to inform the final cytologic interpretation whenever possible. 
GTG-banded karyotypes were obtained by cytogenetic technologists, according to standard procedures using short term culture of fresh cells obtained from the $\mathrm{FNA}^{7}$ and interpreted by a cytogeneticist. A chromosome abnormality was considered clonal if it was present in at least 2 metaphases (in the case of structural or numerical abnormalities) or in at least 3 metaphases (in the case of monosomies). If an abnormal karyotype was obtained, no further FISH testing was performed. When karyotyping was unsuccessful or a normal karyotype was obtained, FISH analysis was performed when judged potentially useful. Interphase FISH can be performed on fixed cell suspensions prepared from uncultured FNA specimens or using whole nuclei extracted from 50 micron sections prepared from paraffin-embedded cell block preparations. In our study, FISH was only performed on uncultured fixed cell suspensions.

Fifty nuclei with discrete FISH signals were analyzed using a 3-color centromeric probe set, according to the manufacturer's instructions (Abbott Molecular, Des Plaines, Ill). The probe set included: D1Z1 (chromosome 1 alpha satellite DNA); D7Z1 (chromosome 7 alpha satellite DNA), and D17Z1 (chromosome 17 alpha satellite DNA). These probes were labeled with Spectrum Orange, Spectrum Aqua, or Spectrum Green, respectively, and were cohybridized. Although these centromeric probes are not specifically designed to classify renal tumors, the combinatorial use of these 3 probes allows for papillary RCC to be distinguished from chromophobe RCC. The rationale for selecting this specific combination of probes is because of several factors. First, because of the limited availability of fluorochromes, a maximum of 3 differentially labeled DNA probes can be cohybridized. Second, the copy number of these 3 chromosomes varies in specific ways between papillary and chromophobe RCCs. Papillary RCC is most frequently associated with disomy 1 , trisomy/tetrasomy 7 , and trisomy $17 .{ }^{8}$ In contrast, chromophobe RCC typically shows monosomy 1 , disomy 7 , and monosomy 17. Accordingly, observing 2 signals for chromosome 1 and 2 signals for chromosome 7 in individual nuclei from tumor cells serves as an internal control for papillary and chromophobe RCC, respectively. Hence, the use of the same 3 constituent probes can be applied to both subtypes of tumors in a diagnostic setting. To establish technical cutoffs, these 3 probes were hybridized to nuclei obtained from clear cell RCCs with 3p- demonstrated cytogenetically. As such, the clear cell RCC specimens were used to establish a cutoff for hybridization of this particular probe cocktail. The normal range for the chromophobe-specific and papillary-specific patterns of hybridization was from $0 \%-2 \%$ and $0 \%-4 \%$, respectively. However, in chromophobe RCC, it is important to be aware that endoreduplication of chromosomes 1 and 17 in a population originally monosomic for both chromosomes will be result in disomy for each. This concomitant finding has also been described cytogenetically. ${ }^{6}$ Finally, the presence of a $t(X ; 18)(p 11 ; q 11)$ translocation, a cytogenetic hallmark for synovial sarcoma, was evaluated using the Vysis LSI SS18 Dual Color Break Apart Rearrangement probes, according to the manufacturer's instructions (Abbott Molecular, Des Plaines, Ill).

\section{RESULTS}

Of the 303 renal FNA specimens analyzed, aspirates with cytologic interpretations of "nondiagnostic" and "atypical" were excluded as these were often acellular or paucicellular specimens, leaving 198 FNA cases subject to analysis in this study (Table 1). In 131 (66\%) of 198, a final interpretation of "positive for malignant cells" was made. Of these, 121 were RCCs and 50, 36, and 9 of them were subclassified as clear cell, papillary, and chromophobe subtypes, respectively. Of the remaining $10 \mathrm{ma}-$ lignant cases, 7 cases were diagnosed as transitional cell carcinoma, 1 as metastatic squamous cell carcinoma, 1 as poorly differentiated carcinoma, and 1 as synovial sarcoma. A final interpretation of "suspicious for malignancy" was rendered in 27 (14\%) of 198 cases, all of which were suspicious for RCC. An interpretation of "neoplastic cells present" was made in 10 (5\%) of 198 cases. In these 10 cases, the diagnosis of "oncocytic neoplasm" was rendered and it was not possible to precisely classify the neoplasm as an oncocytoma, chromophobe RCC, or other oncocytic neoplasm because of insufficient material for ancillary studies. Finally, the interpretation, "negative for malignancy," was made in 30 (15\%) cases: 19 were diagnosed as oncocytoma; 9 as angiomyolipoma; and 2 as metanephric adenoma.

During the on-site assessment, a portion of the needle rinse was allocated for cytogenetic analysis in 74 (37\%) of the 198 cases. Conventional cytogenetics and/or FISH analysis were successful in $44(59 \%)$ cases (Table 2). 
Table 1. Final Cytologic Interpretations of 198 FNA Procedures

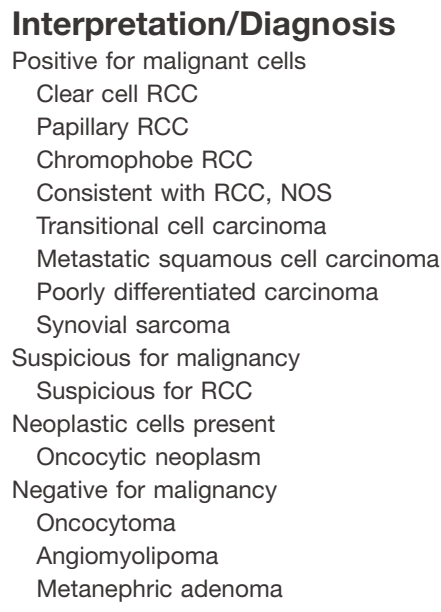

No.
50
36
9
26
7
1
1
1

27
10

19
9
2
198

RCC indicates renal cell carcinoma; NOS, not otherwise specified.

A GTG-banded karyotype was obtained in 30 cases; chromosome aberrations that correlated with specific RCC subtypes were observed in 20 of these. Up to 20 metaphases (range, 3-20) were analyzed and diagnostic karyotypic abnormalities were seen in at least 3 metaphases analyzed (range, 3-15) for each case. Normal or nonspecific karyotypes were seen in the other 10 cases. Although karyotypes could not be obtained in 44 cases, interphase FISH analysis was performed in 14 of these cases and chromosomal abnormalities were detected in 7 of them. Fifty nuclei were counted in these cases and the diagnostic abnormalities were seen in $4(8 \%)$ to $46(92 \%)$ of 50 nuclei.

Specific, abnormal karyotypic or FISH results were seen in 27 cases (Table 3). In 26 of these 27 cases, the results of the cytogenetic analysis were concordant with the cytomorphologic impression of the renal tumor. Specifically, in 2 cases of clear cell RCC, karyotype analysis revealed a deletion of $3 \mathrm{p} /-3$, the cytogenetic hallmark of clear cell RCC (Fig. 1). Trisomy 3, associated with clear cell RCC, ${ }^{9}$ was observed in 1 case of clear cell RCC. A combination of trisomies including those of chromosomes 7 and 17 was observed in 17 cases of papillary RCC (Fig. 2). The presence of trisomy/tetrasomy 7 and trisomy 17 was demonstrated by FISH analysis in 5 additional cases (Fig. 3). In 1 case, FISH analysis revealed the presence of a rearrangement involving 18q11.2 indicative of a
Table 2. Results of Cytogenetics and FISH in 74 Cases

$$
\begin{aligned}
& \text { Results } \\
& \text { Abnormal }^{a} \\
& \text { Karyotype } \\
& \text { FISH } \\
& \text { Normal }^{\text {bononspecific }}{ }^{\text {c }} \\
& \text { Karyotype } \\
& \text { FISH } \\
& \text { Unsuccessful } \\
& \text { Total }
\end{aligned}
$$

No. (\%) 27 (36) 7
FISH indicates fluorescence in situ hybridization.

Specific chromosomal abnormalities corresponding to certain types of renal tumors observed via karyotypic analysis or interphase FISH (performed when karyotyping was unsuccessful).

No chromosomal abnormalities observed by karyotypic analysis or interphase FISH (performed when karyotyping was unsuccessful).

Karyotypic abnormalities were observed; however, the abnormalities were not characteristic of any tumor. FISH was not subsequently performed in these cases.

Karyotypic analysis was unsuccessful and FISH was not subsequently performed in these cases.

Table 3. Common Cytogenetic Abnormalities in Different Subtypes of Renal Tumors and Number of Tumors From This Study That Exhibit These Abnormalities

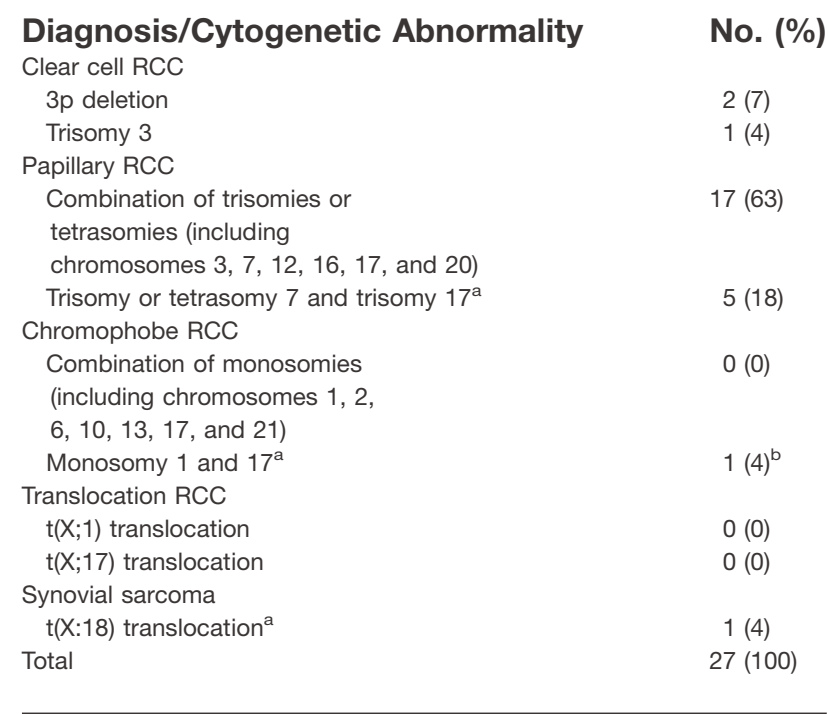

FISH indicates fluorescence in situ hybridization; RCC, renal cell carcinoma.

Obtained by FISH.

In this case, the tumor comprised papillary clusters of oncocytic cells; the diagnosis rendered on the follow-up partial nephrectomy specimen was papillary RCC.

primary renal synovial sarcoma (Fig. 4). Evaluation of the subsequent nephrectomy specimen confirmed a monophasic synovial sarcoma.

Among the 27 cases exhibiting specific, abnormal cytogenetic profiles, there was 1 case of RCC in which the tumor exhibited papillary architecture and comprised cells 


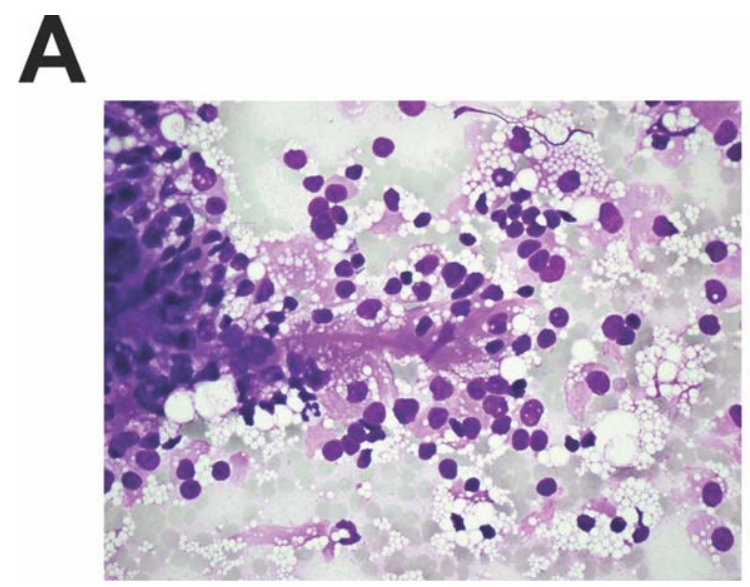

B

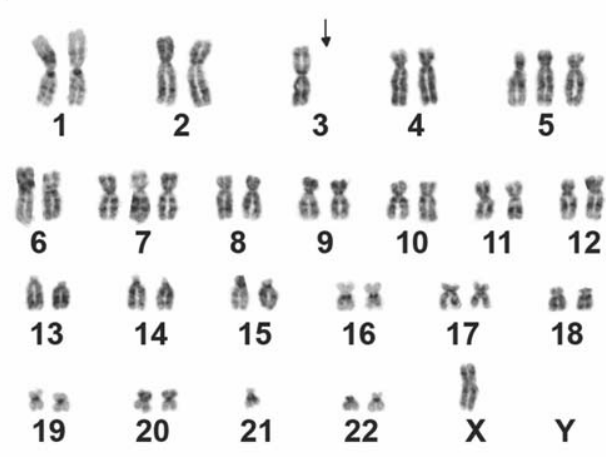

Figure 1. Fine-needle aspiration (FNA) and karyotypic analysis of a clear cell renal cell carcinoma (RCC) are depicted. (A) The air-dried, Hemacolor-stained smear comprises tumor cells with vacuolated cytoplasm and associated with pink, strand-like material. (B) Karyotypic analysis of metaphase chromosomes reveals a deletion of 3p through the loss of chromosome 3 (arrow).
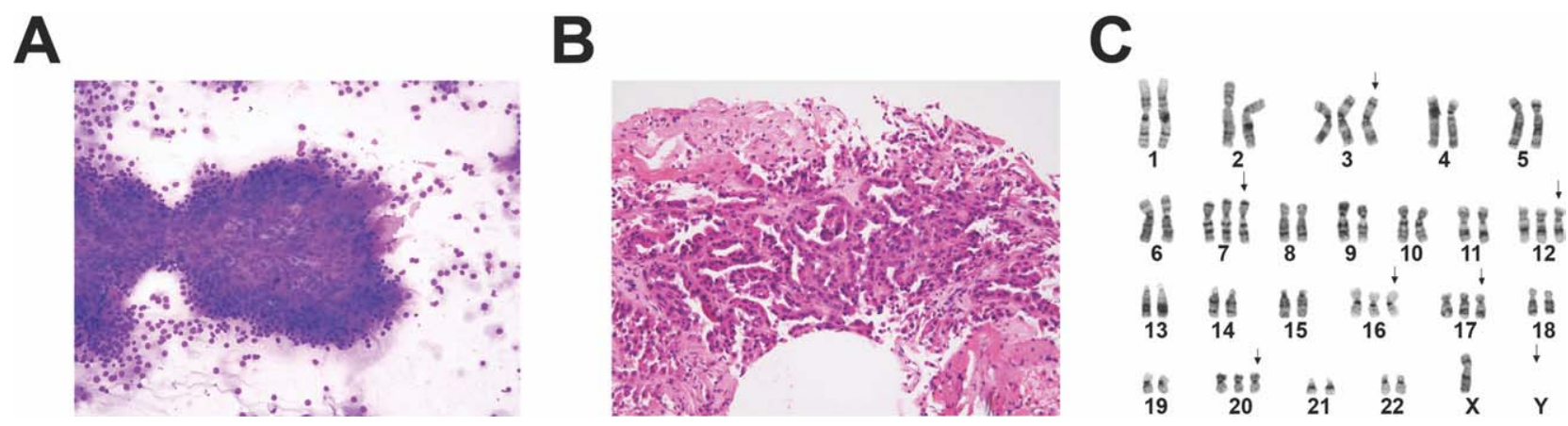

Figure 2. Fine-needle aspiration (FNA) and karyotypic analysis of a papillary renal cell carcinoma (RCC) are depicted. (A) The smear comprises tumor cells arranged in a papillary architecture. (B) The cell block preparation reveals delicate papillae characteristic of a papillary RCC. (C) Karyotypic analysis revealed multiple trisomies involving chromosomes 3, 7, 12, 16, 17, and 20 along with a loss of the $\mathrm{Y}$ chromosome (arrows).

\section{A}

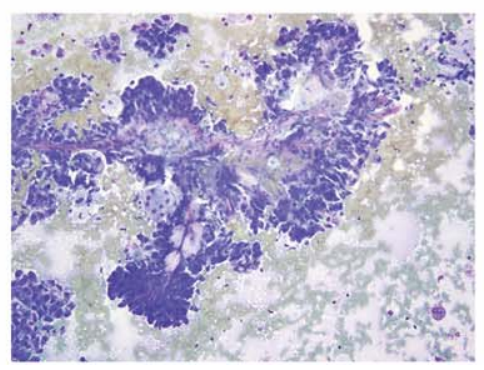

B

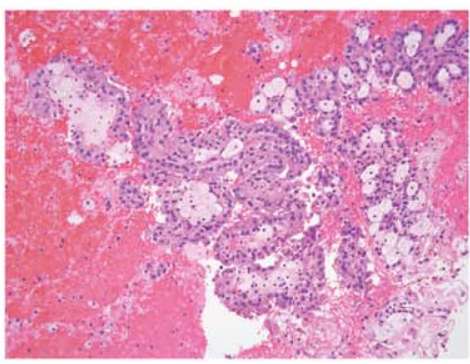

C

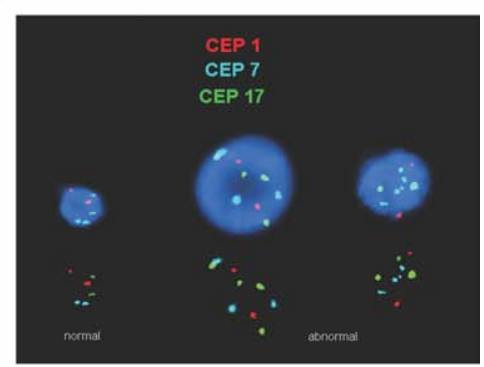

Figure 3. Fine-needle aspiration (FNA) and fluorescence in situ hybridization (FISH) analysis of a papillary renal cell carcinoma (RCC) are depicted. (A) The smear comprises papillary clusters of tumor cells associated with foamy macrophages, also observed in the cell block (B). (C) FISH analysis of the tumor cells revealed trisomy 7 and 17.

with oncocytic cytoplasm (Fig. 5). Because a karyotype could not be obtained, subsequent FISH was performed and revealed monosomies 1 and 17 and 2 copies of chromo- some 7 raising the possibility of a chromophobe RCC (Fig. 5). A partial nephrectomy was subsequently performed and the histopathologic diagnosis was papillary RCC of low 

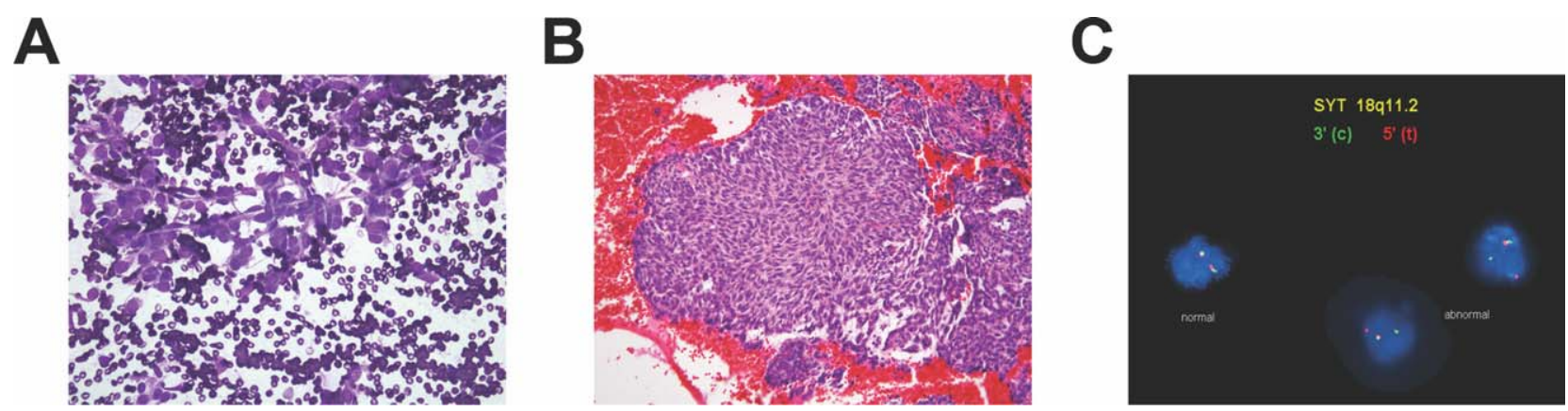

Figure 4. Fine-needle aspiration (FNA) and fluorescence in situ hybridization (FISH) analysis of a synovial sarcoma are depicted. (A) The smear comprises delicate arrays of tumor cells with spindle-shaped hyperchromatic nuclei and scant cytoplasm. (B) The cell block reveals sheets of small, blue, spindle cells similar to those seen in the smear. (C) FISH using a probe for the SYT locus reveals evidence of a breakpoint and rearrangement at 18q11.2.

A

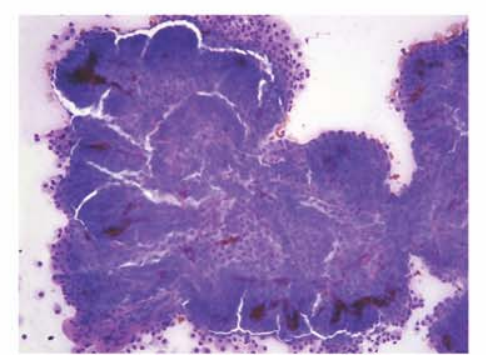

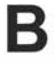

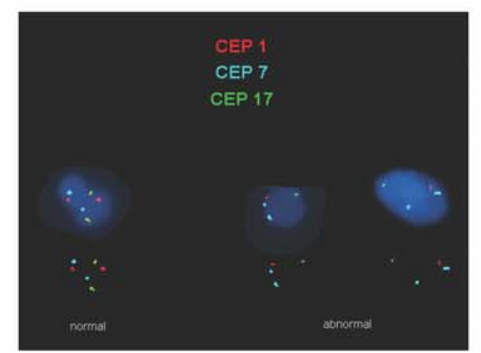

C

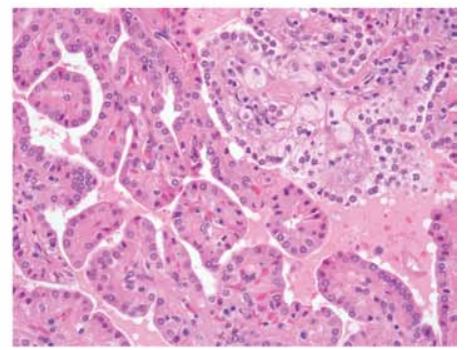

Figure 5. Fine-needle aspiration (FNA) and fluorescence in situ hybridization (FISH) analysis of a papillary renal cell carcinoma (RCC) with oncocytic cells are depicted. (A) The aspirate comprises tumor cells with prominent papillary architecture. At the periphery of the papillae, the oncocytic cytoplasm of the tumor cells can be appreciated. (B) FISH analysis of the tumor cells reveals monosomy 1 and 17. (C) In a section of the subsequently resected tumor, oncocytic cells lining delicate papillae can be observed. Focally, foamy macrophages typical of papillary RCC can be identified.

Fuhrman nuclear grade. Histologically, the tumor was composed of oncocytic cells lining delicate papillae. Focally, there were areas in which the papillary cores were filled with foamy macrophages (Fig. 5). A Hale colloidal iron stain, performed retrospectively on the cell block, was negative (not shown), supporting the diagnosis.

\section{DISCUSSION}

Percutaneous biopsy is the only nonsurgical opportunity to obtain a tissue diagnosis of renal masses. Because renal masses are often biopsied with fine needles alone, rendering an accurate cytologic diagnosis is crucial and can provide important diagnostic information as to the benign or malignant nature of the lesion. Furthermore, subtyping malignant tumors can give insight into prognosis; for example, chromophobe and papillary RCCs have been associated with a better prognosis than other subtypes of
RCCs. ${ }^{10-14}$ Although some renal tumors can be accurately subclassified based on morphologic grounds alone, others can exhibit ambiguous morphologic features rendering subtyping difficult, especially in small biopsies. Therefore, the application of ancillary techniques such as immunohistochemistry and cytogenetics to the subclassification of renal tumors has been a topic of active investigation.

Immunohistochemistry using a panel of markers can be used in the diagnosis and subclassification of renal tumors. ${ }^{15,16}$ This can be applied to smears, cell blocks, and other preparations from FNAs. For instance, papillary and chromophobe RCCs are generally immunoreactive for cytokeratin 7 (CK7), oncocytomas exhibit negative or focal, weak to moderate CK7 expression, and clear cell RCCs are typically negative. Also, vimentin is generally positive in clear cell and papillary RCCs and not in chromophobe RCCs and oncocytomas. Furthermore, alpha-methyl-coenzyme A racemase has been shown to 
strongly highlight papillary RCCs while focally and weakly staining approximately $25 \%$ of clear cell RCCs. ${ }^{16}$ Nonetheless, distinct subtypes of RCCs can occasionally display overlapping immunoprofiles. Because cytogenetics and FISH can reveal diagnostic chromosomal abnormalities specific to certain subtypes of renal tumors, these molecular techniques can complement immunohistochemistry in the subclassification of renal tumors, especially in cases that exhibit morphologic features that overlap between different subtypes. As an illustration, Gobbo et al used FISH in conjunction with immunohistochemistry to accurately subtype RCCs with papillary architecture and comprised of tumor cells with clear cytoplasm. ${ }^{17}$

Conventional cytogenetics and FISH have revealed characteristic chromosomal abnormalities in a variety of renal tumors (Table 3). ${ }^{6}$ For instance, the conventional, clear cell RCC is strongly associated with deletions on chromosome $3 \mathrm{p}$, which harbors tumor suppressor gene loci including the Von Hippel-Lindau (VHL) gene. ${ }^{18-21}$ Loss of $3 \mathrm{p}$ can occur through simple interstitial or terminal deletions, loss of chromosome 3 , and unbalanced translocations. ${ }^{22}$ The papillary subtype of RCC is typically associated with trisomy/tetrasomy 7 , trisomy 17 , and the loss of the $\mathrm{Y}$ chromosome. The presence of only these abnormalities has been associated with lack of metastatic potential. ${ }^{8}$ Additional trisomies of chromosomes 3, 12, 16 , and 20 can be present, ${ }^{23-25}$ and their presence has been associated with increased propensity for local invasion and metastasis. ${ }^{8}$ In contrast to papillary RCCs, chromophobe RCCs are associated with low chromosome number because of specific loss of the second copy of chromosomes $1,2,6,10,13,17$, and $21 .^{26,27}$ In this regard, the detection of multiple monosomies by FISH analysis can be helpful in accurately classifying oncocytic neoplasms on FNA, especially in cases where the distinction of chromophobe RCCs from oncocytomas is difficult because of overlapping cytomorphologic features and/or equivocal results on immunohistochemistry. From a cytogenetic standpoint, oncocytoma can be classified into 3 groups: those with loss of chromosome 1 and/or 14 and 1 sex chromosome, most often the $\mathrm{Y}$ chromosome; those with rearrangement of $11 \mathrm{q} 13$, with $\mathrm{t}(9 ; 11)$ and $\mathrm{t}(5 ; 11)$ among the most frequent translocations observed; and those with heterogeneous abnormalities, including both numerical and structural aberrations. ${ }^{6}$ Finally, the Xp11.2 translocation RCC is recognized as a distinct entity in the 2004 World Health Organization classification of renal tumors. $^{28}$ The most common translocations are $\mathrm{t}(\mathrm{X} ; 1)(\mathrm{p} 11.2 ; \mathrm{q} 21)$ and $\mathrm{t}(\mathrm{X} ; 17)(\mathrm{p} 11.2 ; \mathrm{q} 25)$ resulting in fusions of the TFE3 gene on Xp11.2 with PRCC in 1q21 and $A S P L$ in $17 \mathrm{q} 25$, respectively. ${ }^{29,30}$

In the studies investigating cytogenetic abnormalities in renal tumors, surgically resected material typically represented the source of tumor tissue. To our knowledge, there are no series, to date, that examined the application of cytogenetic analysis to fine-needle specimens, via karyotype analysis and/or FISH, in the diagnosis of renal neoplasms. There are only a few case reports that have addressed the application of cytogenetics/FISH techniques in material obtained from renal FNA specimens. For example, Drut et al used FISH for BCR to diagnose a renal rhabdoid tumor. ${ }^{31}$

We report our experience in interrogating the cytogenetic profiles of renal FNAs. For the cases in which a portion of the FNA had been allocated for concurrent cytogenetic analysis, the results of the karyotypic and FISH analyses were not performed in an independent, blinded fashion. The results of cytogenetic/FISH testing were used to inform the final cytologic interpretation that was released into the electronic medical record (listed in Table 1). Because this study was a retrospective analysis of final cytologic interpretations, it was not possible to determine and quantify the proportion of cases where the results of cytogenetics and FISH resulted in subclassifying cases of "RCC, NOS" or "suspicious for RCC."

Obtaining a karyotype has the advantage of providing a more comprehensive view of chromosome aberrations, such as translocations and chromosomal gains and losses, compared with FISH interrogation of selected chromosomes or chromosomal regions. When the karyotype was uninformative (ie, a normal karyotype or no karyotype was obtained), we used FISH as target probes for centromeric regions of chromosomes 1, 7 and 17 can be used to detect chromosomal gains or losses allowing distinction between papillary and chromophobe RCC, respectively. During the course of this study, we did not use FISH probes to detect high-frequency deletions in $3 p$ for the diagnosis of clear cell RCC. Beroukhim et al demonstrated that, although a variety of loci in 3p can be deleted in clear cell RCC, a significant proportion of these tumors are associated with deletions involving $3 \mathrm{p} 25$, which harbors the VHL gene locus. ${ }^{32}$ Furthermore, FISH using cosmid and P1 probes 
that cover the $V H L$ locus have been shown to detect most deletions in VHL in families with VHL disease. ${ }^{33}$ Accordingly, previous reports have illustrated that in some cases, FISH using bacterial artificial chromosome or cosmid probes can detect deletions in $3 p$ to genetically establish a diagnosis of clear cell RCC. ${ }^{34,35}$

In our series, karyotyping and/or FISH was successful in 44 of the 74 cases where a portion of the FNA was submitted for cytogenetic analysis. Specific, abnormal cytogenetic profiles were seen in 27 of these cases and the results were concordant with the cytomorphologic impression of the renal tumor except in 1 unusual case. In this renal FNA, the tumor consisted of papillary clusters of oncocytic epithelial cells with low-grade nuclei, and FISH analysis revealed 1 copy for the centromeric regions of chromosomes 1 and 17. Although this result was more indicative of chromophobe RCC, the cytomorphologic features of the FNA and the morphology of the tumor in the subsequent surgical resection specimen were most consistent with a papillary RCC. A negative Hale colloidal iron stain supported the diagnosis. As FISH interrogates specific chromosomes, in this case chromosomes 1, 7, and 17 , the status of the remaining chromosomes were not known. Furthermore, the discrepancy in the cytogenetic and cytomorphologic findings could be reconciled in light of a recent report by Lefevre et al describing karyotype deviations of adult papillary renal cell carcinomas with oncocytic cells compared with prototypical papillary RCCs. ${ }^{36}$ Specifically, they reported losses of chromosomes 1,14 , and/or 15 in a small number of these tumors.

In summary, our findings support the feasibility of applying cytogenetics to fine-needle specimens in the diagnosis of renal tumors. On the basis of our experience, conventional karyotypic analysis and FISH can reveal specific chromosomal abnormalities characteristic of commonly encountered renal tumors, especially clear cell and papillary RCCs, as well as unexpected tumors including synovial sarcomas.

\section{CONFLICT OF INTEREST DISCLOSURES}

The authors made no disclosures.

\section{REFERENCES}

1. Kelley CM, Cohen MB, Raab SS. Utility of fine-needle aspiration biopsy in solid renal masses. Diagn Cytopathol. 1996;14:14-19.
2. Silverman SG, Gan YU, Mortele KJ, Tuncali K, Cibas ES. Renal masses in the adult patient: The role of percutaneous biopsy. Radiology. 2006;240:6-22.

3. Tuncali K, vanSonnenberg E, Shankar S, Mortele KJ, Cibas ES, Silverman SG. Evaluation of patients referred for percutaneous ablation of renal tumors: Importance of a preprocedural diagnosis. AJR Am $J$ Roentgenol. 2004;183:575-582.

4. Renshaw AA, Cibas ES. Chapter 14: Kidney and Adrenal Gland. In: Cibas ES, Ducatman BS, eds. Cytology: Diagnostic Principles and Clinical Correlates. Philadelphia, Pa: Saunders/Elsevier, 2009:403-431.

5. Renshaw AA, Lee KR, Madge R, Granter SR. Accuracy of fine needle aspiration in distinguishing subtypes of renal cell carcinoma. Acta Cytologica. 1997;41:987-994.

6. Dal Cin P, Ligon A. Tumors of the Urinary Tract. In: Heim S, Mitelman F, eds. Cancer Cytogenetics. New York: John Wiley \& Sons, Inc.; 2009:465-493.

7. Fletcher JA, Kozakewich HP, Hoffer FA, et al. Diagnostic relevance of clonal cytogenetic aberrations in malignant soft-tissue tumors. N Engl J Med. 1991;324:436-442.

8. Dal Cin P. Genetics in renal cell carcinoma. Curr Opin Urol. 2003;13:463-466.

9. Renshaw AA, Fletcher JA. Trisomy 3 in renal cell carcinoma. Mod Pathol. 1997;10:481-484.

10. Beck SDW, Patel MI, Snyder ME, et al. Effect of papillary and chromophobe cell type on disease-free survival after nephrectomy for renal cell carcinoma. Ann of Surg Oncol. 2004;11:71-77.

11. Cheville JC, Lohse CM, Zincke H, Weaver AL, Blute ML. Comparisons of outcome and prognostic features among histologic subtypes of renal cell carcinoma. $\mathrm{Am} \mathrm{J}$ Surg Pathol. 2003;27:612-624.

12. Cindolo L, De la Taille A, Schips L, et al. Chromophobe renal cell carcinoma: Comprehensive analysis of 104 cases from multicenter European database. Urology. 2005;65:681686.

13. Delahunt B, Bethwaite PB, Nacey JN. Outcome prediction for renal cell carcinoma: evaluation of prognostic factors for tumours divided according to histological subtype. Pathology. 2007;39:459-465.

14. Peyromaure M, Misrai V, Thiounn N, et al. Chromophobe renal cell carcinoma-analysis of 61 cases. Cancer. 2004; 100:1406-1410.

15. Skinnider BE, Folpe AL, Hennigar RA, et al. Distribution of cytokeratins and vimentin in adult renal neoplasms and normal renal tissue - Potential utility of a cytokeratin antibody panel in the differential diagnosis of renal tumors. Am J Surg Pathol. 2005;29:747-754.

16. Zhou M, Roma A, Magi-Galluzzi C. The usefulness of immunohistochemical markers in the differential diagnosis of renal neoplasms. Clin Lab Med. 2005;25:247-257.

17. Gobbo S, Eble JN, MacLennan GT, et al. Renal cell carcinomas with papillary architecture and clear cell components. 
The utility of immunohistochemical and cytogenetical analyses in differential diagnosis. Am J Surg Path. 2008;32:17801786 .

18. Foster K, Prowse A, Vandenberg A, et al. Somatic mutations of the Von Hippel-Lindau disease tumor suppressor gene in nonfamilial clear cell renal carcinoma. Hum Mol Genet. 1994;3:2169-2173.

19. Gnarra JR, Tory K, Weng Y, et al. Mutations of the VHL tumor suppressor gene in renal carcinoma. Nat Genet. 1994; 7:85-90.

20. Shuin T, Kondo K, Torigoe S, et al. Frequent somatic mutations and loss of heterozygosity of the Von HippelLindau tumor suppressor gene in primary human renal cell carcinomas. Cancer Res. 1994;54:2852-2855.

21. Whaley JM, Naglich J, Gelbert L, et al. Germ-line mutations in the Von Hippel-Lindau tumor-suppressor gene are similar to somatic Von Hippel-Lindau aberrations in sporadic renal cell carcinoma. Am J Hum Genet. 1994;55:1092-1102.

22. Balzarini P, Dal Cin P, Roskams T, et al. Histology may depend on the presence of partial monosomy or partial trisomy 3 in renal cell carcinoma. Cancer Genet Cytogenet. 1998;105:6-10.

23. Corless CL, Aburatani H, Fletcher JA, Housman DE, Amin MB, Weinberg DS. Papillary renal cell carcinoma Quantitation of chromosomes 7 and 17 by FISH, analysis of chromosome $3 \mathrm{p}$ for $\mathrm{LOH}$, and DNA ploidy. Diagn Mol Pathol. 1996;5:53-64.

24. Kovacs G. Molecular differential pathology of renal-cell tumors. Histopathology. 1993;22:1-8.

25. Kovacs G, Frisch S. Clonal chromosome-abnormalities in tumor-cells from patients with sporadic renal cell carcinomas. Cancer Res. 1989;49:651-659.

26. Kovacs A, Kovacs G. Low chromosome-number in chromophobe renal cell carcinomas. Genes Chromosomes Cancer. 1992;4:267-268.

27. Speicher MR, Schoell B, Dumanoir S, et al. Specific loss of chromosomes 1, 2, 6, 10, 13, 17, 21 in chromophobe renal cell carcinomas revealed by comparative genomic hybridization. American J Pathol. 1994;145:356-364.

28. Eble JN, Sauter G, Epstein JI, Sesterhenn IA, eds. World Health Organization classification of tumours: pathology and genetics of tumours of the urinary system and male genital organs. Lyon, France: IARCC Press; 2004.

29. Argani P, Antonescu CR, Illei PB, et al. Primary renal neoplasms with the ASPL-TFE3 gene fusion of alveolar soft part sarcoma-a distinctive tumor entity previously included among renal cell carcinomas of children and adolescents. Am J Pathol. 2001;159:179-192.

30. Sidhar SK, Clark J, Gill S, et al. The $\mathrm{t}(\mathrm{X} ; \mathrm{l})(\mathrm{p} 11.2 ; \mathrm{q} 21.2)$ translocation in papillary renal cell carcinoma fuses a novel gene PRCC to the TFE3 transcription factor gene. Hum Mol Genet. 1996;5:1333-1338.

31. Drut R, Drut RM. Renal and extrarenal congenital rhabdoid tumor: diagnosis by fine-needle aspiration biopsy and FISH. Diagn Cytopathol. 2002;27:32-34.

32. Beroukhim R, Brunet JP, Di Napoli A, et al. Patterns of gene expression and copy-number alterations in Von-Hippel Lindau disease-associated and sporadic clear cell carcinoma of the kidney. Cancer Res. 2009;69:4674-4681.

33. Pack SD, Zbar B, Pak E, et al. Constitutional von Hippel-Lindau (VHL) gene deletions detected in VHL families by fluorescence in situ hybridization. Cancer Res. 1999;59: 5560-5564.

34. Yamaguchi $S$, Yoshihiro $S$, Matsuyama $H$, et al. The allelic loss of chromosome 3p25 with c-myc gain is related to the development of clear cell renal cell carcinoma. Clin Genet. 2003;63:184-191.

35. Barocas DA, Mathew S, DelPizzo JJ, et al. Renal cell carcinoma sub-typing by histopathology and fluorescence in situ hybridization on a needle-biopsy specimen. BJU International. 2006;99:290-295.

36. Lefevre M, Couturier J, Sibony M, et al. Adult papillary renal tumor with oncocytic cells - Clinicopathologic, immunohistochemical, and cytogenetic features of 10 cases. Am J Surg Pathol. 2005;29:1576-1581. 